\title{
Effects of Mo, Cr, and V Additions on Tensile and Charpy Impact Properties of API X80 Pipeline Steels
}

\author{
SEUNG YOUB HAN, SANG YONG SHIN, CHANG-HYO SEO, HAKCHEOL LEE, \\ JIN-HO BAE, KISOO KIM, SUNGHAK LEE, and NACK J. KIM
}

\begin{abstract}
In this study, four API X80 pipeline steels were fabricated by varying $\mathrm{Mo}, \mathrm{Cr}$, and $\mathrm{V}$ additions, and their microstructures and crystallographic orientations were analyzed to investigate the effects of their alloying compositions on tensile properties and Charpy impact properties. Because additions of Mo and $\mathrm{V}$ promoted the formation of fine acicular ferrite (AF) and granular bainite (GB) while prohibiting the formation of coarse GB, they increased the strength and upper-shelf energy (USE) and decreased the energy transition temperature (ETT). The addition of Cr promoted the formation of coarse GB and hard secondary phases, thereby leading to an increased effective grain size, ETT, and strength, and a decreased USE. The addition of V resulted in a higher strength, a higher USE, a smaller effective grain size, and a lower ETT, because it promoted the formation of fine and homogeneous of AF and GB. The steel that contains $0.3 \mathrm{wt}$ pet Mo and 0.06 wt pct $\mathrm{V}$ without $\mathrm{Cr}$ had the highest USE and the lowest ETT, because its microstructure was composed of fine $\mathrm{AF}$ and $\mathrm{GB}$ while its maintained excellent tensile properties.
\end{abstract}

DOI: $10.1007 / \mathrm{s} 11661-009-9884-3$

(C) The Minerals, Metals \& Materials Society and ASM International 2009

\section{INTRODUCTION}

THE consumption of petroleum and natural gas has been increasing, in line with upgraded standards of living and industrial advancements. As oil drilling and transportation from regions of extreme conditions such as Siberia, Alaska, and the depths of the oceans increase, pipeline steels have been widely used in lowtemperature environments. ${ }^{[1]}$ In order to stably use pipeline steels at low temperatures, excellent lowtemperature properties are critical. The strength of structural steels increases in general with decreasing temperatures, but their toughness decreases abruptly. Thus, much research has been actively conducted in the hope of achieving enhanced low-temperature toughness and strength. ${ }^{[2-4]}$

Pipeline steels are classified into API grades by the American Petroleum Institute (Washington, DC), based on their yield strength, as obtained from tensile tests. It is important to evaluate the structural integrity of the steels in regard to their microstructure, in order to

SEUNG YOUB HAN and CHANG-HYO SEO, Research Assistants, and SANG YONG SHIN, Postdoctoral Research Associate, are with Center for Advanced Aerospace Materials, Pohang University of Science and Technology, Pohang, 790-784, Korea. HAKCHEOL LEE, Researcher, is with the Plate Research Group, Technical Research Laboratories, POSCO, Pohang, 790-785, Korea. SUNGHAK LEE and NACK J. KIM, Professors, Center for Advanced Aerospace Materials, Pohang University of Science and Technology, are jointly appointed with Materials Science and Engineering, Pohang University of Science and Technology. Contact e-mail: shlee@postech.ac.kr JIN-HO BAE, Principal Researcher, and KISOO KIM, Group Leader, are with the Sheet Products \& Process Research Group, Technical Research Laboratories, POSCO, Pohang 790-785, Korea.

Manuscript submitted October 31, 2008.

Article published online June 16, 2009 develop new high-strength, high-toughness pipeline steels. Charpy V-notch (CVN) impact tests and dropweight tear tests (DWTT) have been used as important testing methods for guaranteeing the required ductile fracture resistance. ${ }^{[5,6]}$ Presently, the CVN upper-shelf energy (USE) and the 85 pct shear-appearance transition temperature measured by DWTT are the standards most widely used to evaluate the resistance to ductile fracture and the fracture propagation transition temperature, respectively, of pipeline steels. These testing methods have correlated well with the actual fracture propagation behavior of conventional pipeline steels that have a CVN USE below $100 \mathrm{~J} \cdot{ }^{[7,8]}$ This correlation has become less obviousness, however, with phenomena such as the rising upper shelf, ${ }^{[9]}$ separation, ${ }^{[10]}$ and abnormal fracture appearance ${ }^{[3]}$ occurring during DWTT, because the toughness of pipeline steels has been greatly improved through manufacturing advancements such as controlled rolling and accelerated cooling. As a way to solve this problem, Chevron notch or static precracked DWTT specimens, the notch of which is adjusted so that the fracture-initiation energy is lower than that of the standard pressed-notch DWTT specimen, are used for testing high-toughness pipeline steels. ${ }^{[11]}$ However, the CVN impact test is still most widely used as a simple way to measure the toughness and transition temperature of pipeline steels.

Pipeline steels used in low-temperature environments should have transition temperatures low enough to prevent abrupt brittle fracture and absorbed energy high enough to prevent unstable ductile fracture propagation. ${ }^{[1-4]}$ Impact absorbed energy and strength are affected by microstructural factors such as the type, volume fraction, and shape of secondary phases, grain sizes, and matrix structures. The transition temperature 
is largely affected by the unit crack path, which is the distance between cleavage fracture facets and is closely related to the effective grain size. ${ }^{[12-15]}$ Because API X80-grade pipeline steels, which are widely used, have various microstructures and mechanical properties, depending on their chemical compositions, it is necessary to systematically investigate their microstructures and properties according to different chemical compositions.

In the present study, API X80 pipeline steels that are rolled in the single-phase region and that have different microstructures were fabricated by varying additions of $\mathrm{Mo}, \mathrm{Cr}$, and $\mathrm{V}$, and their tensile properties and Charpy impact properties were investigated. The effective grain size was analyzed using the electron backscatter diffraction (EBSD) method, to examine the correlation between the microstructural factors and mechanical properties due to variations in the alloying compositions.

\section{EXPERIMENTAL}

\section{A. API X80 Pipeline Steels}

The steels used in this study were API X80-grade steels with minimum yield strength levels of $552 \mathrm{MPa}$ (80 ksi); their chemical compositions are shown in Table I. Four API X80 steels were fabricated by varying the amounts of $\mathrm{Mo}, \mathrm{Cr}$, and $\mathrm{V}$. According to the amounts of the $\mathrm{Mo}, \mathrm{Cr}$, and $\mathrm{V}$ additions, for convenience, the steels are referred to as $3 \mathrm{MCV}, 1 \mathrm{MCV}, 3 \mathrm{MV}$, and $3 \mathrm{MC}$ (Table I). An overall grain refinement effect was expected by rolling with a high rolling reduction ratio (over $80 \mathrm{pct}$ ) in the nonrecrystallized region of austenite, after austenitization at $1150{ }^{\circ} \mathrm{C} .{ }^{[3,4]}$ This high rolling reduction ratio leads to an increase in dislocation density and subsequent grain refinement, because dislocations act as ferrite initiation sites during cooling. ${ }^{[16,17]}$ The rolling of all of the four steels was finished at the temperature of the austenite single-phase region above $\mathrm{Ar}_{3}$. After the finish rolling, the steels were rapidly cooled from $790{ }^{\circ} \mathrm{C}$ to the finish cooling temperatures of $550{ }^{\circ} \mathrm{C}$ to $\sim 650{ }^{\circ} \mathrm{C}$ at a cooling rate of $10^{\circ} \mathrm{C} / \mathrm{s}$ to $\sim 15^{\circ} \mathrm{C} / \mathrm{s}$. The final plate thickness was $15 \mathrm{~mm}$. The schematic illustration of the rolling and cooling conditions is shown in Figure 1.

\section{B. Microstructural Analysis}

The steels were polished and etched in a 2 pct nital solution; the microstructures of the longitudinaltransverse (L-T) planes were observed by an optical

Table I. Chemical Composition of Four API X80 Steels Investigated (Weight Percent)

\begin{tabular}{lcccccccc}
\hline Steel & C & Si & Mn & P & S & Mo & Cr & V \\
\hline 3MCV & 0.08 & 0.24 & 1.9 & 0.011 & 0.003 & 0.3 & 0.3 & 0.06 \\
1MCV & & & & & & 0.1 & 0.3 & 0.06 \\
3MV & & & & & & 0.3 & - & 0.06 \\
3MC & & & & & & 0.3 & 0.3 & - \\
\hline
\end{tabular}

microscope and a scanning electron microscope (SEM) (model S-4300E, resolution $0.2 \mu \mathrm{m}$, Hitachi High Technologies, Tokyo).

\section{Tensile and Charpy Impact Tests}

Tensile and Charpy impact specimens were obtained from the $1 / 2$ thickness location of the rolled plate. Round tensile specimens with a gage diameter of $6 \mathrm{~mm}$ and a gage length of $30 \mathrm{~mm}$ were prepared in the transverse direction, and were tested at room temperature at a crosshead speed of $5 \mathrm{~mm} / \mathrm{min}$ by an Instron machine (model Instron 8801, Instron Corp., Canton, MA) with a $100-\mathrm{kN}$ capacity. ${ }^{[18]}$ Charpy impact tests were performed on standard CVN specimens (size $10 \times 10 \times 55 \mathrm{~mm}$, orientation transverse-longitudinal) in the temperature range $-196{ }^{\circ} \mathrm{C}$ to $20^{\circ} \mathrm{C}$, using a Tinius Olsen impact tester with a $500-\mathrm{J}$ capacity (model FAHC-J-500-01, JT Toshi, Tokyo). ${ }^{[19]}$ In order to reduce errors in the data interpretation, a regression analysis for absorbed impact energy vs test temperature was conducted with a hyperbolic tangent curve-fitting method. ${ }^{[20]}$ Based on the regression analysis data, the energy transition temperature (ETT), which corresponds to the average value of the USE and lower-shelf energy, was determined. In order to examine the cleavage fracture unit and crack propagation path, the fracture surface and the cross-sectional area beneath the fracture surface of the Charpy specimens fractured at $-196{ }^{\circ} \mathrm{C}$ were observed by an SEM, after the fracture surface was coated by nickel.

\section{EBSD Analysis}

The EBSD analysis (resolution $0.2 \mu \mathrm{m}$ ) was conducted on the cross-sectional area beneath the fracture surface of the Charpy impact specimens fractured at $-196{ }^{\circ} \mathrm{C}$, by a field-emission SEM (model S-4300SE, Hitachi High Technologies, Tokyo). ${ }^{[21]}$ The data were

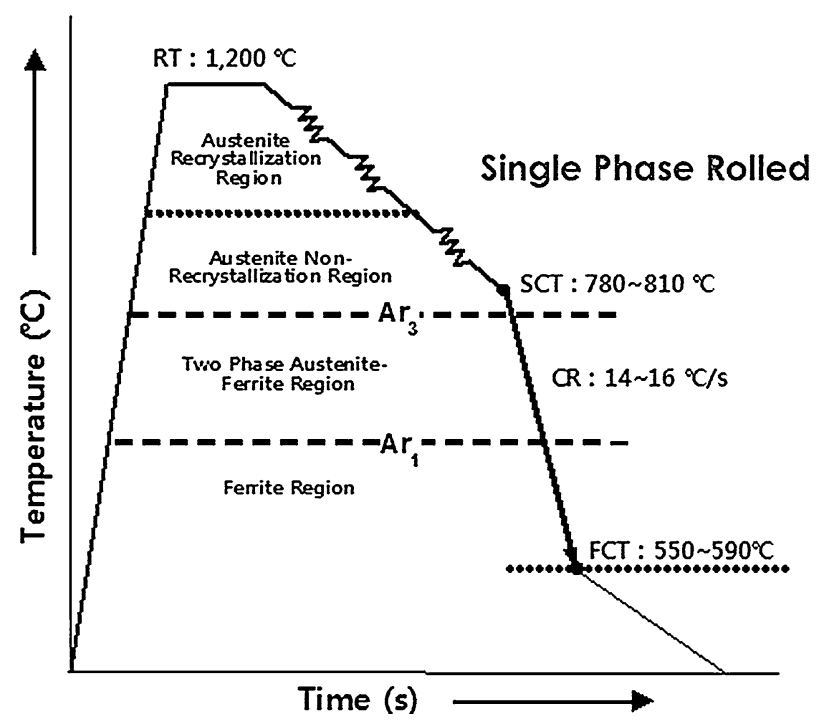

Fig. 1-Schematic illustration of rolling and cooling conditions of API X80 steels. 
then interpreted by orientation imaging microscopy (OIM) analysis software, which was provided by TexSEM Laboratories, Inc. (TSL OIM Data Analysis package v 5.2, Provo, UT).

\section{RESULTS}

\section{A. Microstructure}

Figures 2(a) through (d) and 3(a) through (d) are optical microscope (OM) and SEM micrographs of the four kinds of rolled steels, respectively. Various phases present in the microstructure were marked in the micrographs, and their volume fraction was measured as shown in Table II. The $\mathrm{Cr}, \mathrm{Mo}$, and $\mathrm{V}$ increase the pearlite start temperature $\left(P_{S}\right)$ and decrease the bainite start temperature $\left(B_{S}\right)$; in addition, all the steels were finish rolled in the austenite region and then watercooled at a fast cooling rate. These steels were largely composed of acicular ferrite (AF) together with granular bainite (GB), martensite (M), and martensite-austenite (MA) constituents, and retained austenite (RA). ${ }^{[22-29]}$ The AF is an acicular microstructure formed inside austenite grains and contains MA constituents at irregularly shaped grain boundaries. The GB contains equiaxed, island-shaped MA constituents and has well-developed substructures inside. ${ }^{[2,23]}$ Its grains are relatively large and its grain boundaries are not clearly identified; the microstructures of the rolled steels in this study were analyzed in terms of these morphological categories. Figure 4 shows an example of the microstructure of the $1 \mathrm{MCV}$ steel with AF, GB, and secondary phases. Here, $\mathrm{AF}$ and $\mathrm{GB}$ are marked as black and green areas, respectively, using a Adobe Photoshop CS2 program (Adobe Systems Inc., San Jose, CA). At least five micrographs were analyzed for each steel; the volume fractions of the AF, GB, and secondary phases were measured using an image analyzer. In the 3MCV steel, fine AF grains which are smaller than $2 \mu \mathrm{m}$ in size are primarily observed, while GB grains which are smaller than $10 \mu \mathrm{m}$ in size are homogeneously dispersed. The volume fraction of GB is 20 pct, which is the highest of all the steels (Figures 2(a) and 3(a)). In the 1MCV steel, the volume fractions of the GB and secondary phases are 8 and 1.2 pct, respectively, which are the lowest of all the steels, but a number of coarse GB grains are found over $30 \mu \mathrm{m}$ in size (Figures 2(b) and 3(b)). Similar to the $1 \mathrm{MCV}$ steel, the $3 \mathrm{MV}$ steel is evenly composed of fine $\mathrm{AF}$ and $\mathrm{GB}$ (Figures 2(c) and 3(c)). In the $3 \mathrm{MC}$ steel, GB grains which are over $30 \mu \mathrm{m}$ in size are coarsely formed, similar to the $1 \mathrm{MCV}$ steel, and the
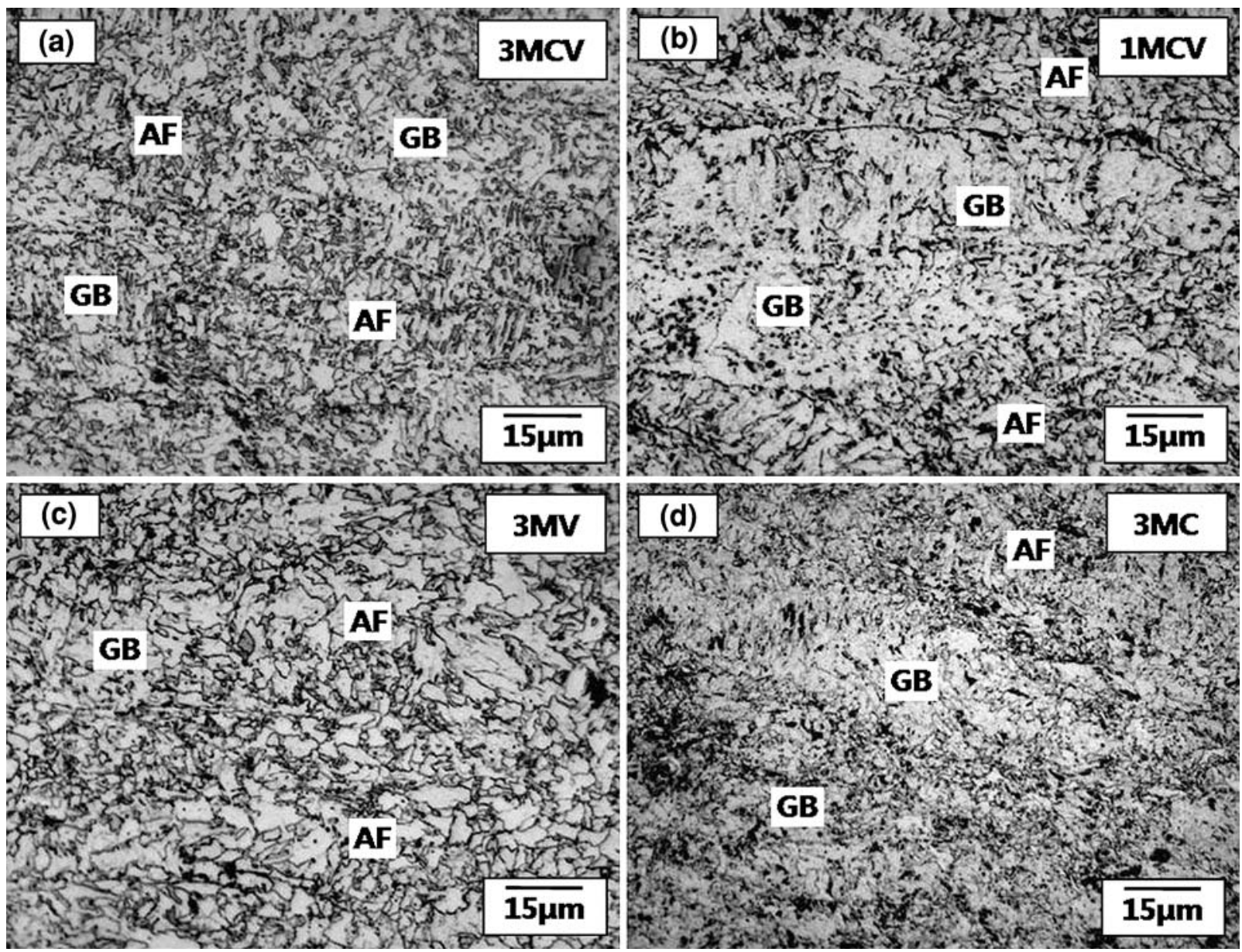

Fig. 2-Optical micrographs of $(a) 3 \mathrm{MCV},(b) 1 \mathrm{MCV},(c) 3 \mathrm{MV}$, and $(d) 3 \mathrm{MC}$ steels, showing their L-T plane microstructures. Nital etched. 

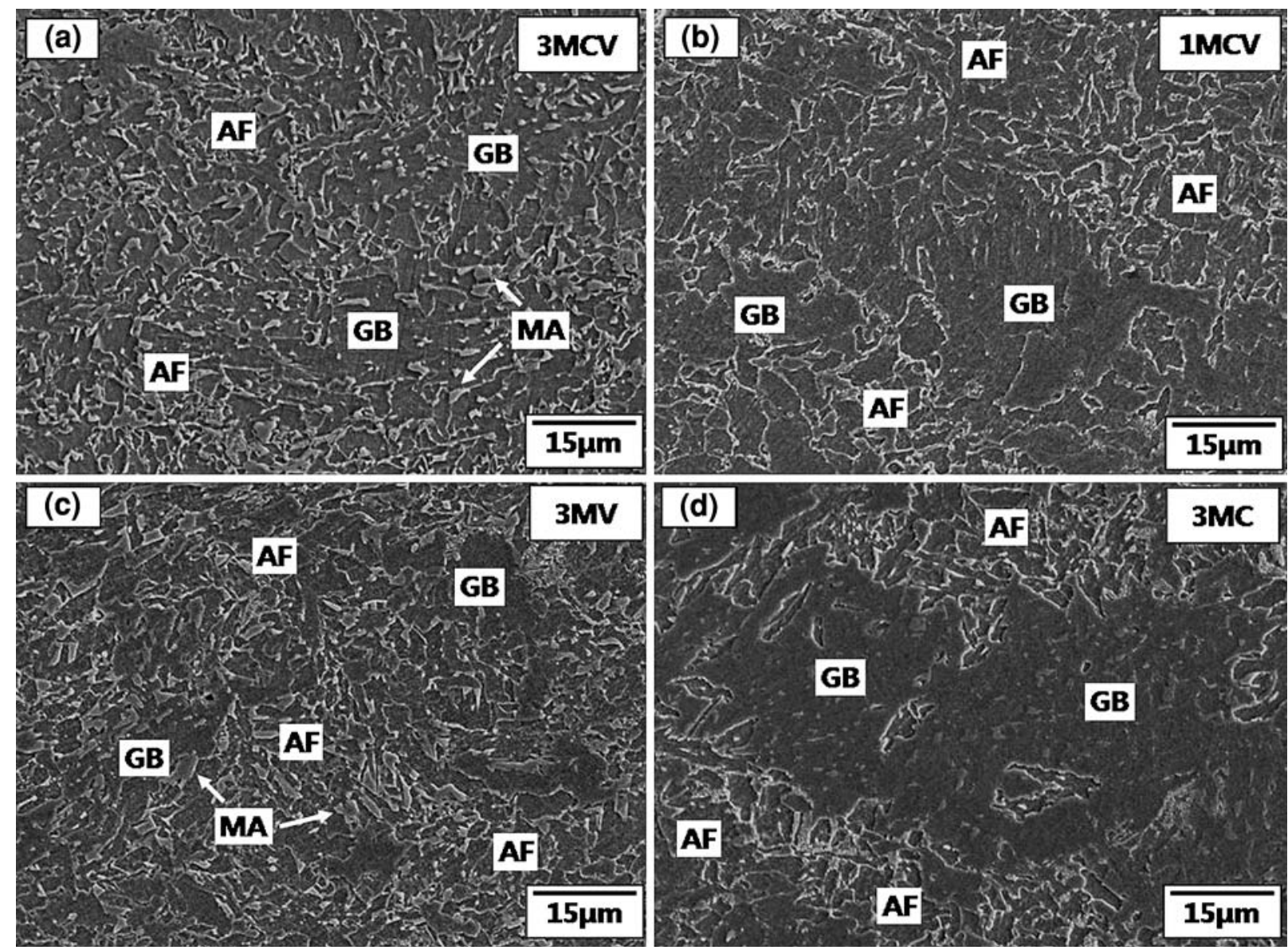

Fig. 3-SEM micrographs of (a) 3MCV, (b) 1MCV, (c) 3MV, and (d) 3MC steels, showing their L-T plane microstructures. Nital etched.

Table II. Volume Fractions of AF, GB, and Secondary Phases Present in the Steels

\begin{tabular}{lccc}
\hline Steel & $\begin{array}{c}\text { AF } \\
\text { (Pct) }\end{array}$ & $\begin{array}{c}\text { GB } \\
\text { (Pct) }\end{array}$ & $\begin{array}{c}\text { Secondary } \\
\text { Phases* (Pct) }\end{array}$ \\
\hline $3 \mathrm{MCV}$ & balance & 19.5 & 2.3 \\
$1 \mathrm{MCV}$ & balance & 7.5 & 1.2 \\
$3 \mathrm{MV}$ & balance & 15.5 & 1.7 \\
$3 \mathrm{MC}$ & balance & 18.1 & 6.0 \\
\hline
\end{tabular}

*Secondary phases include cementite, M, and MA constituents.

volume fraction of secondary phases is high, at approximately 6 pct (Figures 2(d) and 3(d)). In all the steels, fine $\mathrm{AF}$ grains which are smaller than $2 \mu \mathrm{m}$ in size are formed. Some GB grains which are larger than $30 \mu \mathrm{m}$ in size are coarsely formed in the $1 \mathrm{MCV}$ and $3 \mathrm{MC}$ steels; in the other two steels, they are finely formed and are less than $10 \mu \mathrm{m}$ in size.

\section{B. Room-Temperature Tensile Properties}

Figures 5(a) through (d) show room-temperature stress-strain curves; the tensile properties obtained from them are listed in Table III. The $3 \mathrm{MCV}$ and $3 \mathrm{MC}$ steels show continuous yielding behavior, whereas the other two steels show discontinuous yielding behavior. Kim et al. ${ }^{[24]}$ explained the effect of hard secondary

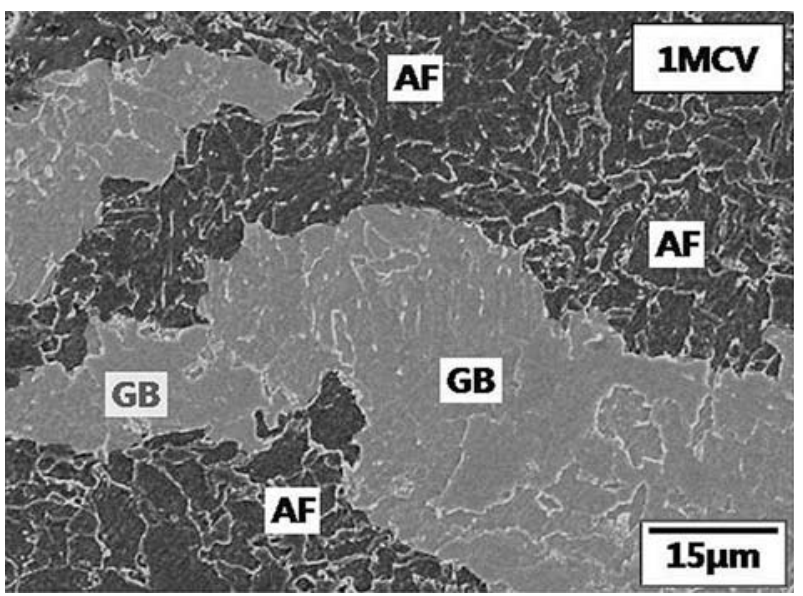

Fig. 4-SEM micrograph of $1 \mathrm{MCV}$ steel containing AF and GB. The AF and GB are marked as black and green areas, respectively, using a Adobe Photoshop CS2 program.

phases on the yield behavior of AF-based structures. An increase in the volume fraction of hard secondary phases such as M or MA is associated with continuous yielding behavior and higher tensile strength, because the increased volume fraction of hard secondary phases promotes mobile dislocations at boundaries between the hard secondary phases and the nearby soft phases. 


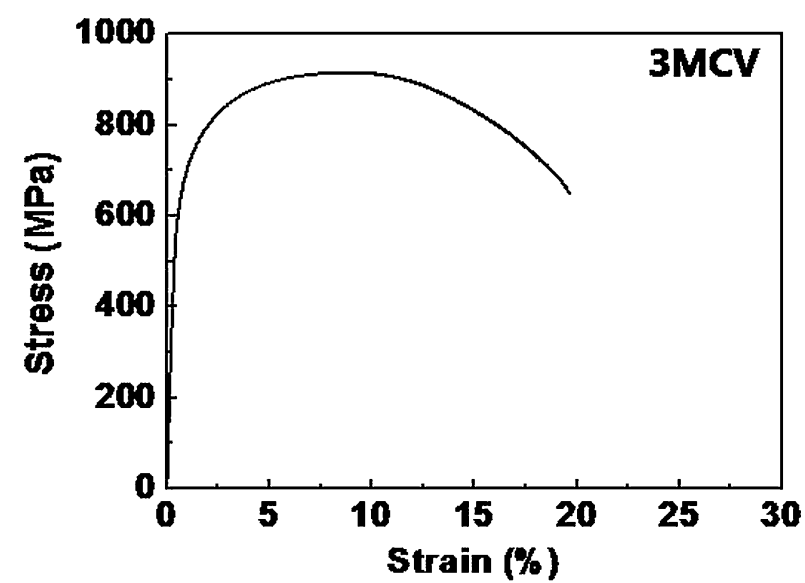

(a)

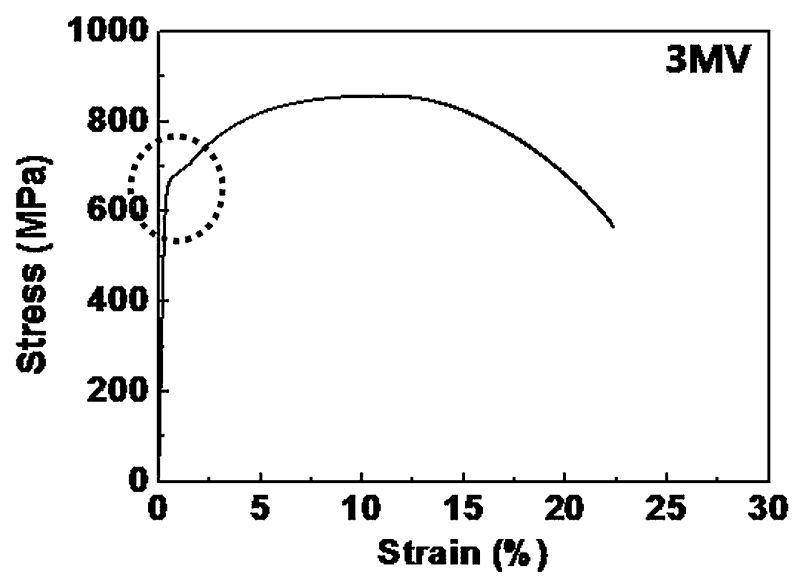

(c)

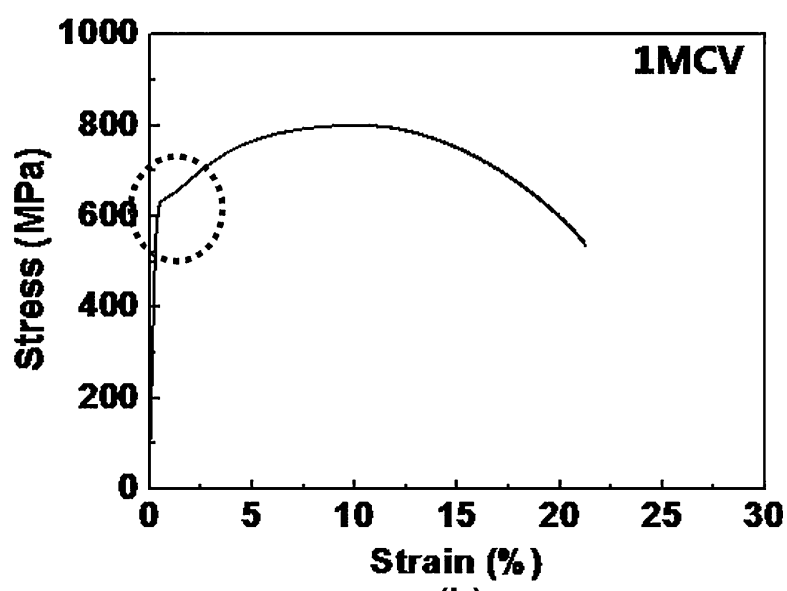

(b)

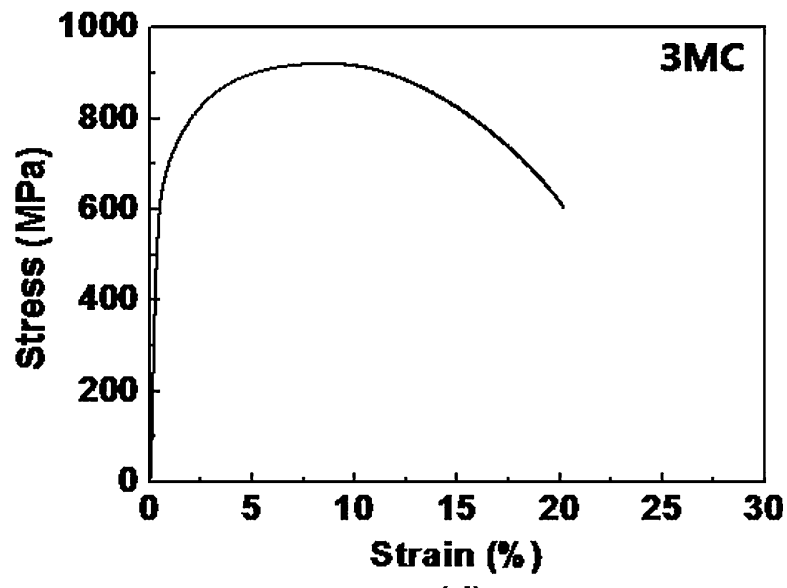

(d)

Fig. 5-Stress-strain curves obtained from room-temperature tensile test of $(a) 3 \mathrm{MCV},(b) 1 \mathrm{MCV},(c) 3 \mathrm{MV}$, and $(d) 3 \mathrm{MC}$ steels.

Table III. Room-Temperature Tensile Properties of the Steels

\begin{tabular}{lcccc}
\hline Steel & $\begin{array}{c}\text { Yield } \\
\text { Strength } \\
(\mathrm{MPa})\end{array}$ & $\begin{array}{c}\text { Tensile } \\
\text { Strength } \\
(\mathrm{MPa})\end{array}$ & $\begin{array}{c}\text { Elongation } \\
(\text { Pct })\end{array}$ & $\begin{array}{c}\text { Yield } \\
\text { Ratio } \\
(\text { Pct })\end{array}$ \\
\hline $3 \mathrm{MCV}$ & 635 & 924 & 20 & 69 \\
$1 \mathrm{MCV}$ & 637 & 802 & 21 & 79 \\
$3 \mathrm{MV}$ & 669 & 853 & 22 & 78 \\
$3 \mathrm{MC}$ & 609 & 913 & 20 & 67 \\
\hline
\end{tabular}

In the present study, the $1 \mathrm{MCV}$ and $3 \mathrm{MV}$ steels with a relatively low volume fraction of secondary phases show discontinuous yielding behavior. All the steels show yield strengths of $600 \mathrm{MPa}$ or above and thus satisfy the strength requirement of $551 \mathrm{MPa}(80 \mathrm{ksi})$ for the API $\mathrm{X} 80$ steel. The tensile strength of the $3 \mathrm{MCV}$ and $3 \mathrm{MC}$ steels is approximately $920 \mathrm{MPa}$; this is higher than that of the $1 \mathrm{MCV}$ and $3 \mathrm{MV}$ steels $(800$ to $\sim 850 \mathrm{MPa})$. The yield ratio of the $3 \mathrm{MCV}$ and $3 \mathrm{MC}$ steels, which show continuous yielding behavior and a great difference between their yield strength and tensile strength, is lower than that of the $1 \mathrm{MCV}$ and $3 \mathrm{MV}$ steels. The elongation of all the steels is nearly the same, at approximately 20 pet.

\section{Charpy Impact Properties}

Figures 6(a) through (d) show the Charpy absorbed energy data as a function of the test temperature from which the USE and ETT were obtained, as listed in Table IV. The USE of the $3 \mathrm{MCV}$ and $3 \mathrm{MV}$ steels is high, at 230 to $\sim 240 \mathrm{~J}$, it decreases in the $1 \mathrm{MCV}$ and $3 \mathrm{MC}$ steels. The $3 \mathrm{MV}$ steel has the lowest ETT, at $-99^{\circ} \mathrm{C}$, and shows the most excellent low-temperature impact properties. The other three steels have nearly the same ETT, at approximately $-70{ }^{\circ} \mathrm{C}$.

Figures 7(a) through (d) and 8(a) through (d) show SEM fractographs of the Charpy impact specimens fractured at $-196{ }^{\circ} \mathrm{C}$ and SEM micrographs of the cross-sectional area beneath the cleavage fracture surface, respectively. In all the steels, cleavage facets are observed. Particularly in the $1 \mathrm{MV}$ and $3 \mathrm{MC}$ steels, in which the GB is coarsely formed, large cleavage facets over $30 \mu \mathrm{m}$ in size are found, as indicated by the dotted circles in Figures 7(b) and (d). An examination of the cleavage crack propagation path beneath the crosssectioned fracture surface reveals the path change at interfaces between the microstructures (Figures 8(a) through (d)). Because the grains are fine and homogeneously dispersed in the $3 \mathrm{MCV}$ and $3 \mathrm{MV}$ steels, the unit crack path is short, at less than $10 \mu \mathrm{m}$ (Figures 8(a) and 


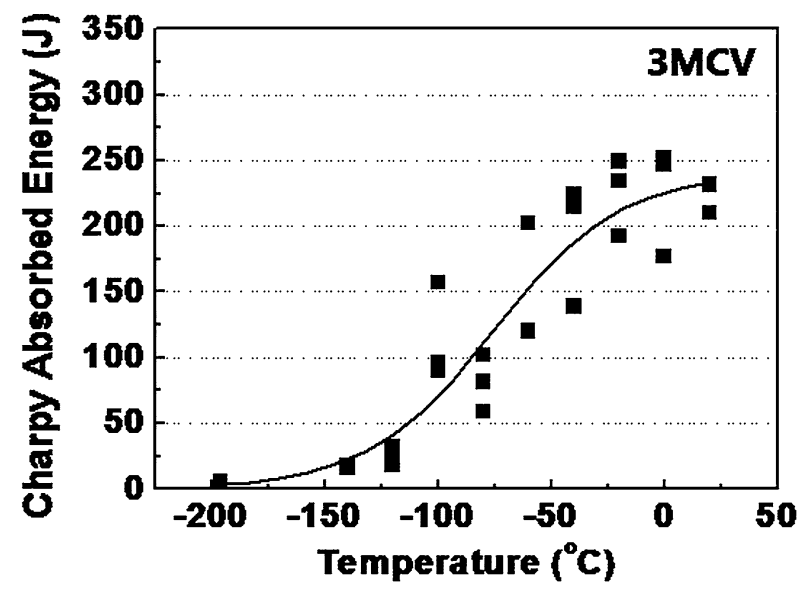

(a)

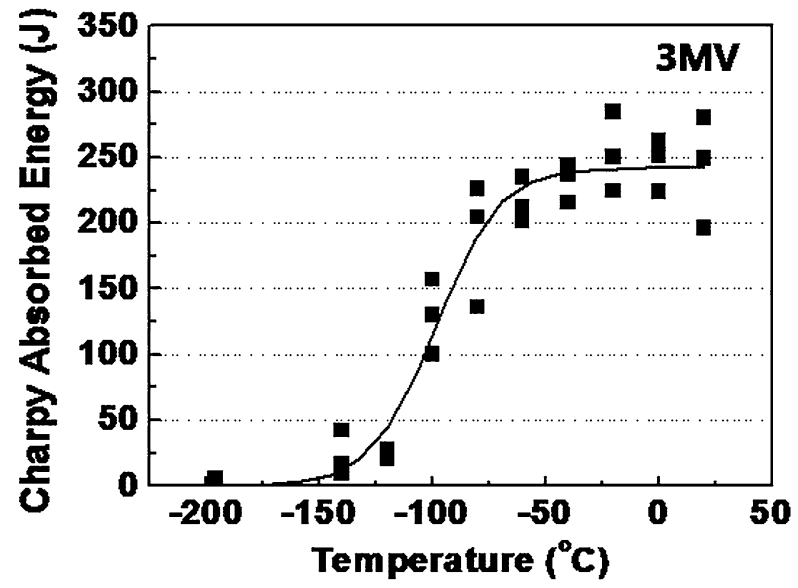

(c)

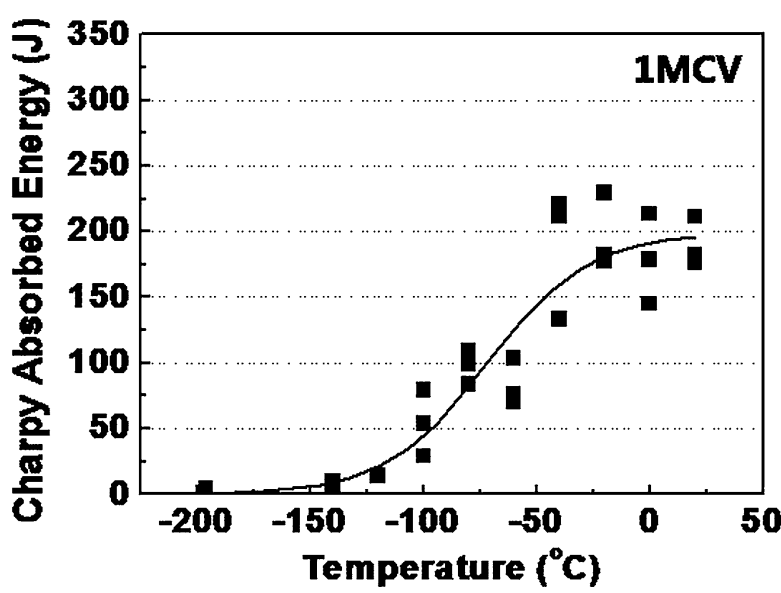

(b)

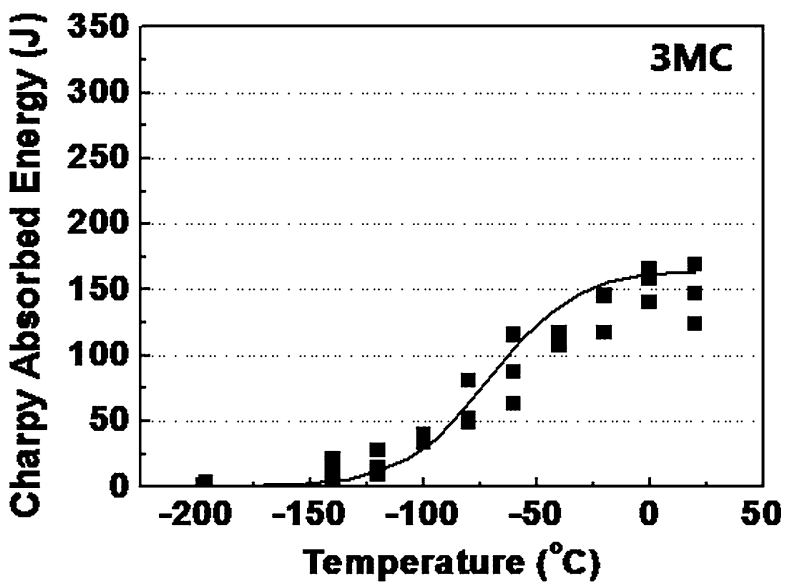

(d)

Fig. 6 - Charpy absorbed energy $v$ s test temperature of (a) 3MCV, (b) $1 \mathrm{MCV},(c) 3 \mathrm{MV}$, and (d) 3MC steels.

Table IV. Charpy Impact Test Results of the Steels

\begin{tabular}{lcc}
\hline Steel & USE $(\mathrm{J})$ & ETT $\left({ }^{\circ} \mathrm{C}\right)$ \\
\hline $3 \mathrm{MCV}$ & 231 & -75 \\
1MCV & 199 & -72 \\
$3 \mathrm{MV}$ & 242 & -99 \\
$3 \mathrm{MC}$ & 166 & -70 \\
\hline
\end{tabular}

(c)). However, the unit crack path is 10 to $\sim 30 \mu \mathrm{m}$ long in the 1MCV steel because of the presence of coarse GB (Figure $8(\mathrm{~b})$ ). The $3 \mathrm{MC}$ steel shows a long unit crack path of approximately $30 \mu \mathrm{m}$, because it contains largesized GB (Figure 8(d)).

\section{DISCUSSION}

The microstructures of steels vary with the alloying composition. The Mo, an element for enhanced hardenability, interrupts the carbon diffusion by raising the diffusion activation energy of carbon; it also expands the carbon-rich region inside the austenite, which leads to an increased MA volume fraction as the carbon-rich regions are transformed into MA during cooling. ${ }^{[25]}$
Also, the Mo addition prevents the formation of upper bainite, promotes GB formation, and makes the microstructures dense and the grains fine by reducing the $B_{s}$, bainite finish temperature $\left(B_{f}\right)$ and the $\mathrm{M}$ start temperature $\left(M_{s}\right) .{ }^{[25]}$ In the present study, the $3 \mathrm{MCV}$ steel with a large amount ( $0.3 \mathrm{wt}$ pct) of Mo has very fine grains; in the $3 \mathrm{MCV}$ steel the volume fractions of GB and MA are approximately twice as high as those of the $1 \mathrm{MCV}$ steel.

The $\mathrm{Cr}$ works as an element for hardenability and a ferrite stabilizer. From the phase diagram of $\mathrm{Fe}-\mathrm{Cr}$, it is understood that an addition of only 0.4 wt pet of $\mathrm{Cr}$ stabilizes ferrite in the temperature range $780{ }^{\circ} \mathrm{C}$ to $790{ }^{\circ} \mathrm{C}$. Thus, the transformation from austenite to ferrite would proceed very actively during holding in this temperature range. Moreover other elements such as $\mathrm{C}$ and $\mathrm{Mn}$ could be solutionized into austenite and may enhance the formation of RA. ${ }^{[26-28]}$ This is the reason that the $3 \mathrm{MCV}$ steel that contains $\mathrm{Cr}$ shows a higher volume fraction of GB and MA than the $3 \mathrm{MV}$ steel (Table II). According to the repulsive interaction working between $\mathrm{Cr}$ and $\mathrm{Mo}$ atoms in steels, fine structures can be obtained by the addition of both $\mathrm{Mo}$ and $\mathrm{Cr}$ as $\mathrm{AF}$ and $\mathrm{GB}$ are homogeneously dispersed. ${ }^{[29]}$ In the $1 \mathrm{MCV}$ steel that contains $0.1 \mathrm{wt}$ pet of Mo, coarse GB 

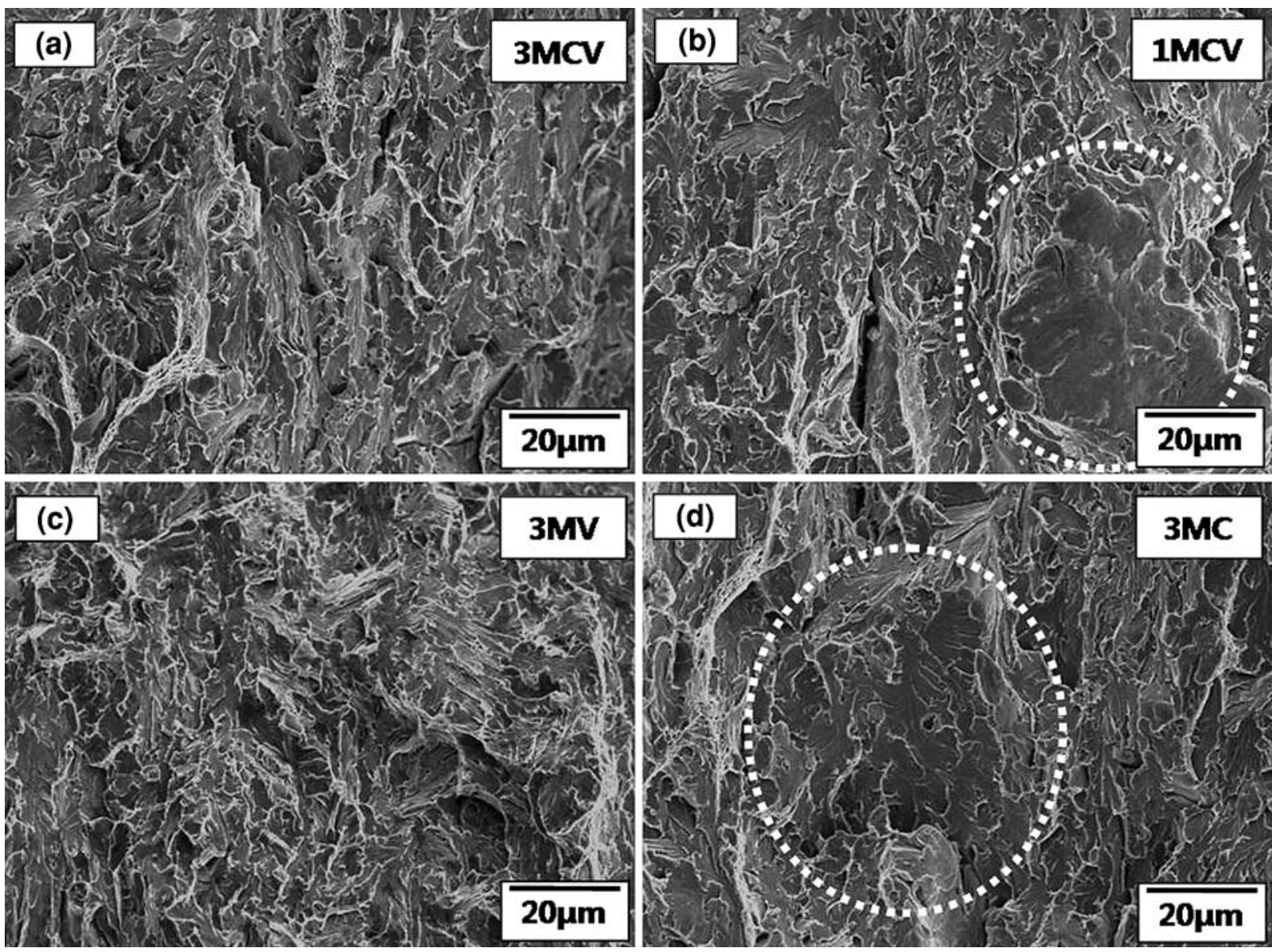

Fig. 7- SEM fractographs of Charpy impact specimens fractured at $-196{ }^{\circ} \mathrm{C}$ for $(a) 3 \mathrm{MCV},(b) 1 \mathrm{MCV},(c) 3 \mathrm{MV}$, and $(d) 3 \mathrm{MC}$ steels. Dotted circular areas in (b) and (d) indicate large cleavage facets $(>30 \mu \mathrm{m})$.

grains are observed. On the other hand, AF and GB are formed finely and homogenously in the $3 \mathrm{MCV}$ steel that contains 0.3 wt pet (Figures 2 and 3).

The addition of $\mathrm{V}$ activates the initial nucleation of ferrite in the austenite region and effectively prevents the formation of $\mathrm{Cr}$ carbonitrides in the $\mathrm{GB}$. The grains become refined and the strength is considerably enhanced. ${ }^{[24-28]}$ The $3 \mathrm{MCV}$ and $3 \mathrm{MV}$ steels have finer and more homogeneously dispersed GB; thus, they have finer grains overall than the other two steels. The effects of the alloying elements can be summarized as follows. ${ }^{[24,26]}$ (1) The Mo addition enhances strength and toughness by promoting the ready formation of low-temperature transformation phases and grain refinement. (2) The $\mathrm{Cr}$ enhances strength, because it promotes low-temperature transformation phases but deteriorates low-temperature toughness due to the coarse grain size. (3) The $\mathrm{V}$ addition is effective in enhancing both strength and toughness, because it increases the volume fraction of secondary phases and refines the grains. In order to simultaneously enhance both strength and toughness, therefore, it is recommended that Mo and $\mathrm{V}$ be added but $\mathrm{Cr}$ be reduced.

The strength of materials is affected by their microstructure; the microstructure varies with the alloying composition. The effects of the chemical composition on strength can be analyzed by studying the correlation between the microstructure and the tensile properties. A higher volume fraction of hard phases and a finer grain size lead to higher strength. ${ }^{[26-31]}$ Because secondary phases such as MA are transformed rapidly at the lowest temperatures, they are very strong; GB, on the other hand, formed at a somewhat faster cooling rate than $\mathrm{AF}$, contains more dislocations inside and thus shows slightly higher strength than AF. ${ }^{[22,23]}$ Figure 9 presents the correlation between the tensile strength and the GB volume fraction. The tensile strength increases when movable dislocations formed at low-temperature transformation phases such as GB move toward grain boundaries and get mingled with secondary phases. ${ }^{[13,14]}$ The tensile strength is less sensitive to the grain size but more sensitive to the volume fraction of $\mathrm{GB}$ or secondary phases. Thus, the $3 \mathrm{MCV}$ steel with $\mathrm{GB}$ and second-phase volume fractions of 19.5 and 2.3 pct, respectively, and the $3 \mathrm{MC}$ steel with GB and secondary volume fractions of 18.1 and 6 pct, respectively, show high tensile strength, at more than $900 \mathrm{MPa}$. On the other hand, the 1MCV steel, with the lowest GB and secondary-phase volume fractions, shows the lowest tensile strength, at $800 \mathrm{MPa}$. Consequently, in order to achieve a high yield strength, it is necessary to refine the grains by reducing the $\mathrm{GB}$ with the reduction in $\mathrm{Cr}$ and 

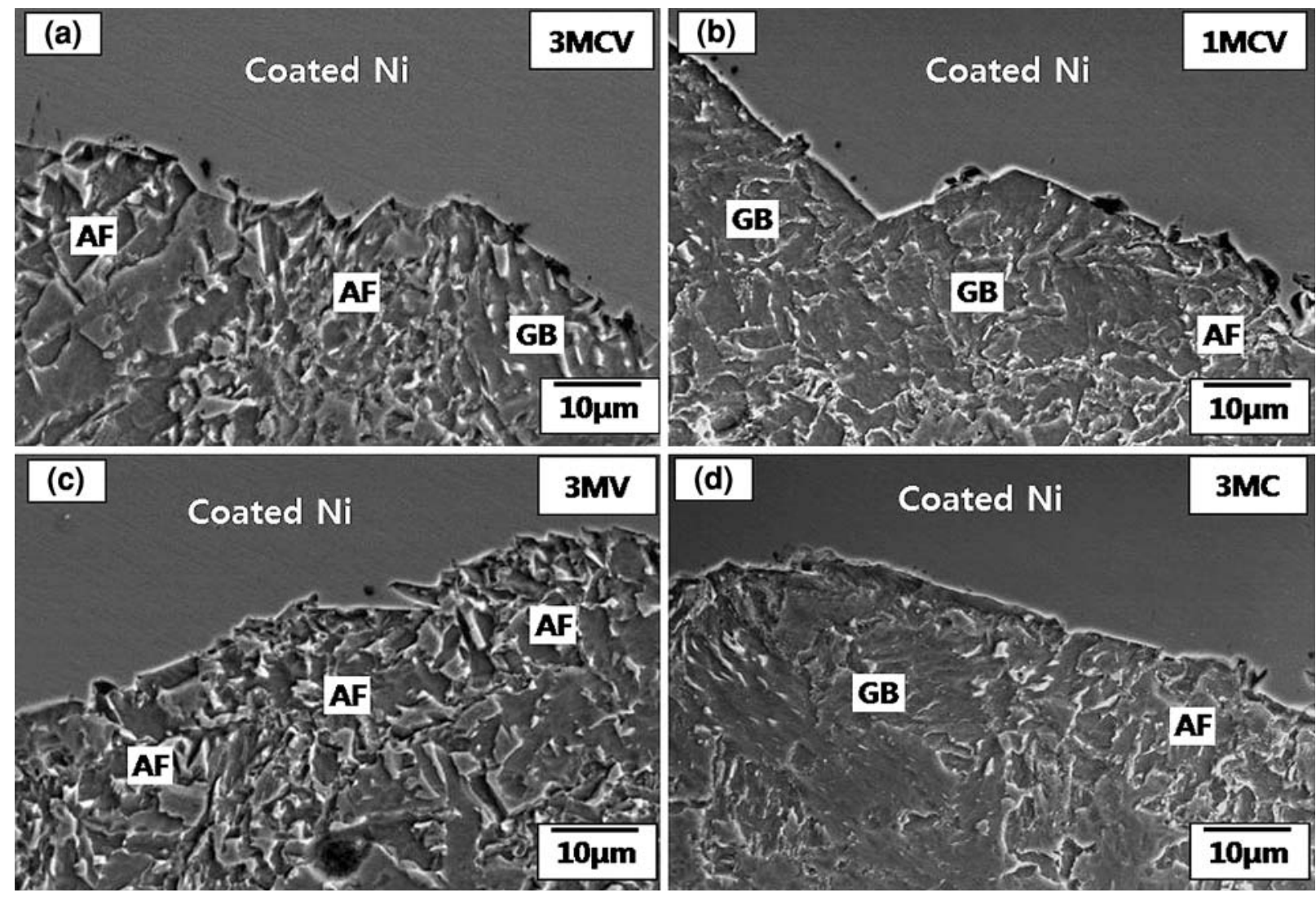

Fig. 8 - SEM micrographs of cross-sectional area beneath the cleavage fracture surface of Charpy impact specimens fractured at $-196{ }^{\circ} \mathrm{C}$ for $(a)$ $3 \mathrm{MCV},(b) 1 \mathrm{MCV},(c) 3 \mathrm{MV}$, and $(d) 3 \mathrm{MC}$ steels, showing crack propagation path. Fractured surfaces were coated by Ni.

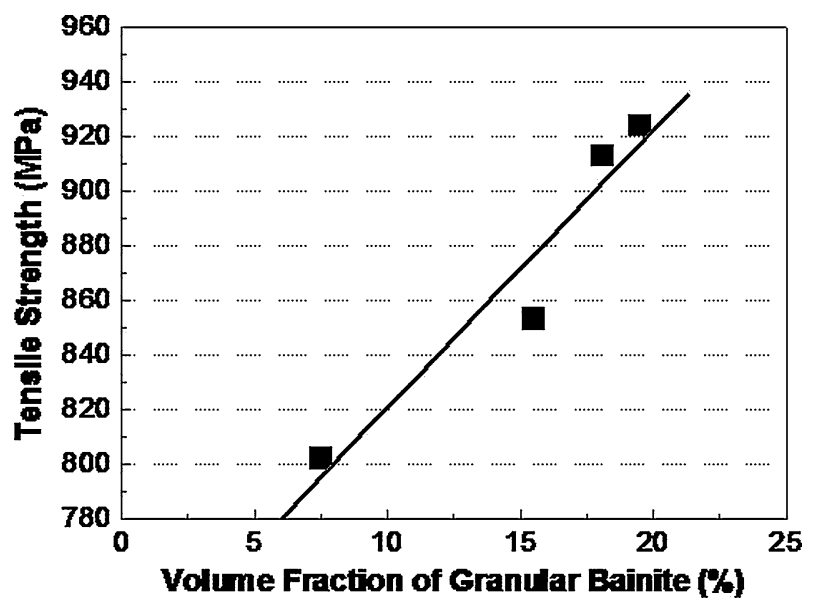

Fig. 9-Relationship between tensile strength and volume fraction of GB.

the addition of $\mathrm{V}$, such as in the $3 \mathrm{MV}$ steel. For a higher tensile strength, the increase in the GB and secondaryphase volume fraction by adding sufficient hardenability elements, such as in the $3 \mathrm{MCV}$ steel, is desirable.

The USE is affected by the type, volume fraction, and size of the microstructure, while the ETT is affected mainly by the effective grain size. ${ }^{[4,32]}$ The toughness of steels is enhanced with an increasing volume fraction of microstructures that have excellent toughness and a decreasing grain size. ${ }^{[3]}$ The GB has a lower toughness and a larger grain size than the matrix structure of AF. ${ }^{[22,23]}$ Figure 10 shows the USE data as a function of the volume fraction of $\mathrm{GB}$, in consideration of the grain size. The USE tends to decrease with the increasing volume fraction of GB, as marked by the blue arrow. The USEs of the $3 \mathrm{MCV}$ and $3 \mathrm{MV}$ steels, which have fine and homogeneous grains and a relatively low secondaryphase volume fraction, range from 230 to $240 \mathrm{~J}$, while those of the coarse-grained $1 \mathrm{MCV}$ and $3 \mathrm{MC}$ steels are 199 and $166 \mathrm{~J}$, respectively (Table IV). These values of the coarse-grained $1 \mathrm{MCV}$ and $3 \mathrm{MC}$ steels are lower by approximately $60 \mathrm{~J}$ than the expected USE values based on the GB volume fraction alone; this reduction in USE is marked by the arrows in Figure 10. To achieve excellent USE in pipeline steels, it is thus necessary to refine grains by increasing their Mo and V content; it is also necessary to prevent the formation of coarse GB by decreasing the $\mathrm{Cr}$ content.

In order to analyze low-temperature toughness in terms of microstructural factors, Pickering et al. ${ }^{[33]}$ represented the transition temperature $(T)$ obtained from the Charpy impact test as in the following equation:

$$
T=f(\text { composition })+g(\text { strength })-11.5 \cdot(d)^{-1 / 2}
$$

Here, $f$ (composition) refers to the function of chemical composition and hardenability, $g$ (strength) refers to that 


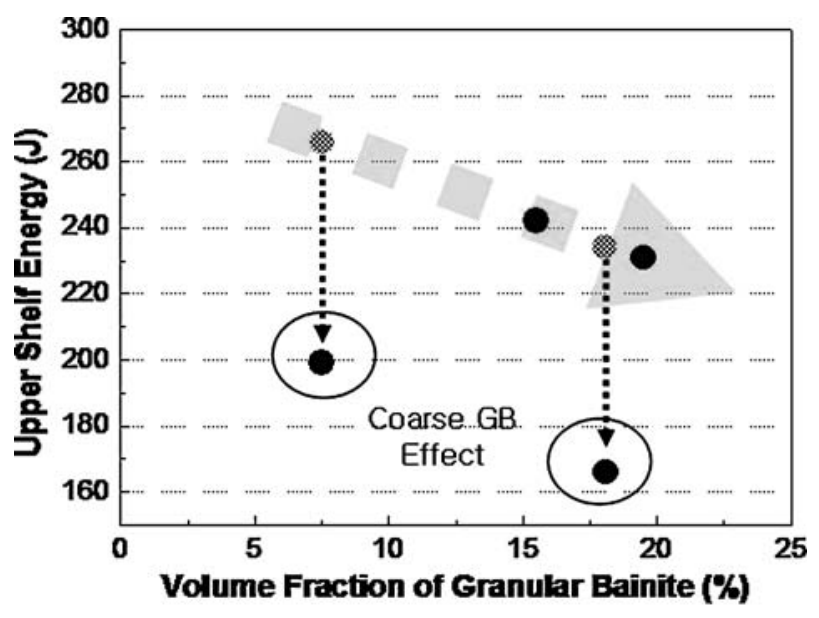

Fig. 10-Relationship between USE and volume fraction of GB.
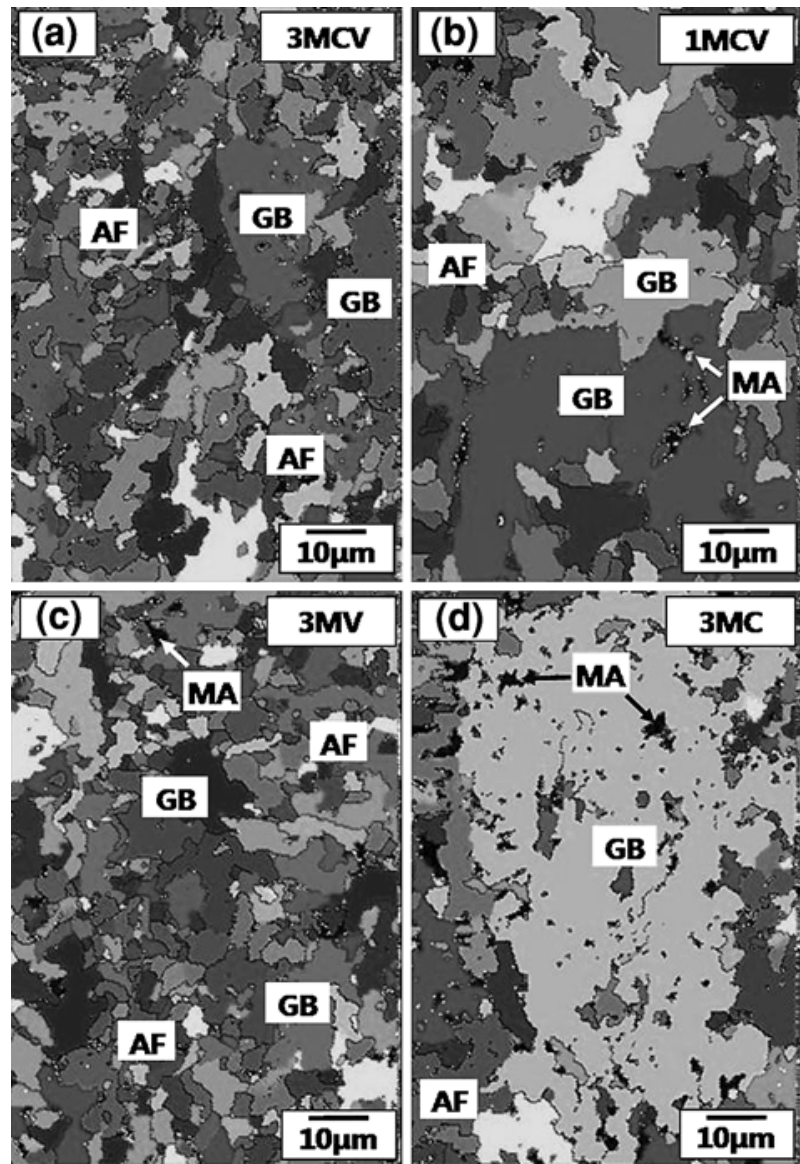

Fig. 11-Misorientation maps of (a) 3MCV, (b) 1MCV, (c) 3MV, and (d) $3 \mathrm{MC}$ steels, showing grains with high-angle $(\geq 15 \mathrm{deg})$ boundaries.

of strength, and $d$ refers to the grain size. This equation indicates that the transition temperature rises with increasing hardenability elements, strength, and grain size.

To analyze the grain size, the misorientations between grains were analyzed by EBSD. Inverse pole figure maps are shown in Figures 11(a) through (d), and high-angle

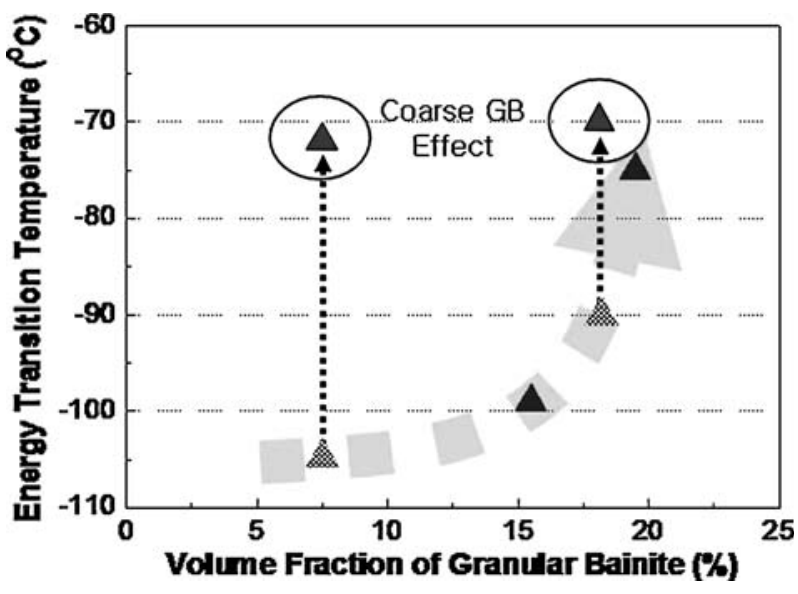

Fig. 12-Relationship between ETT and volume fraction of GB.

( $\geq 15 \mathrm{deg}$ ) grain boundaries are marked in dark lines. In the $3 \mathrm{MCV}$ and $3 \mathrm{MV}$ steels, the overall effective grain size is small (the grain sizes of AF and GB are 5 and $10 \mu \mathrm{m}$, respectively), but the GB size in the $1 \mathrm{MCV}$ and $3 \mathrm{MC}$ steels is very coarse, at over $30 \mu \mathrm{m}$.

Figure 12 shows the correlation between the ETT and the volume fraction of $\mathrm{GB}$ that has a larger effective grain size than the matrix structure of AF. The ETT tends to increase as the GB volume fraction increases (blue arrow). The $3 \mathrm{MV}$ and $3 \mathrm{MCV}$ steels, the effective grain size of which is small due to the formation of fine GB, show a lower ETT than the $3 \mathrm{MV}$ and $3 \mathrm{MCV}$ steels, which have low tensile strength due to a low volume fraction of GB and secondary phases. On the other hand, the $1 \mathrm{MCV}$ and $3 \mathrm{MC}$ steels that contain coarse GB $(\geq 30 \mu \mathrm{m}$ in size) are formed and show poor lowtemperature toughness and a high ETT $\left(-70{ }^{\circ} \mathrm{C}\right)$ because of their larger effective grain size in spite of their lower volume fraction of GB and secondary phases as compared to the $3 \mathrm{MC}$ and $3 \mathrm{MCV}$ steels. The increase in ETT due to grain coarsening in the $1 \mathrm{MCV}$ and $3 \mathrm{MC}$ steels is marked with an arrow in Figure 12; because of the grain coarsening, the ETT is expected to increase by $20{ }^{\circ} \mathrm{C}$ to $\sim 30{ }^{\circ} \mathrm{C}$. The AF shows excellent low-temperature toughness because it has a short unit crack path and, thus, excellent resistance to crack propagation. The $\mathrm{GB}$, formed coarsely, in general, has a long unit crack path and low resistance to crack propagation; it thus shows poor low-temperature toughness. ${ }^{[4,15]}$ This is because AF grains are high angled and thus have a fine effective grain size, whereas subgrains inside the GB are coalesced into one and, consequently, the effective grain size of the GB increases. ${ }^{[24,34,35]}$ According to Figures 8(a) through (d), which show the cleavage fracture propagation path of the Charpy impact specimens tested at $-196{ }^{\circ} \mathrm{C}$, it can be confirmed that GB with a unit crack path of approximately $30 \mu \mathrm{m}$, longer than that of the AF (less than $5 \mu \mathrm{m}$ ), shows lower resistance to crack propagation than does the AF.

Figures 13(a) through (d) show the distribution of grain-boundary misorientations, from which the average grain-boundary angle and the fraction of high-angle $(\geq 15 \mathrm{deg})$ grain boundaries were measured. Based on 


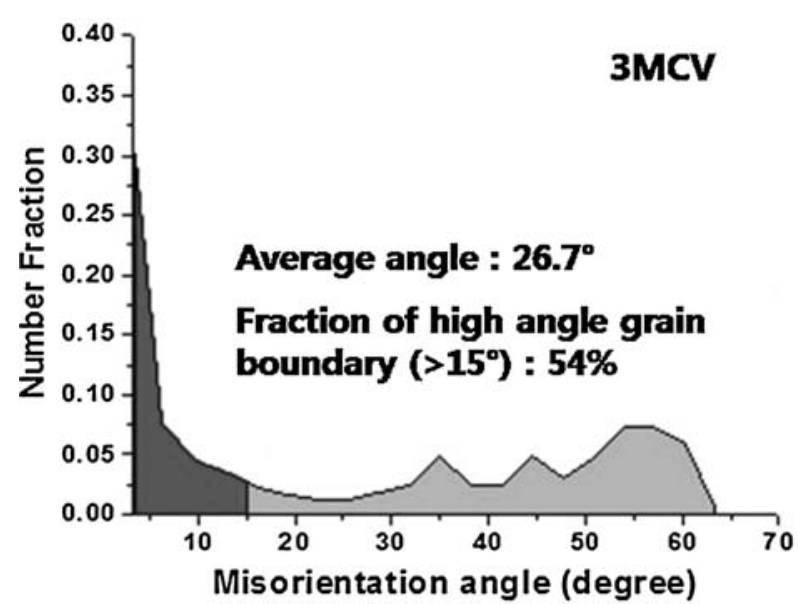

(a)

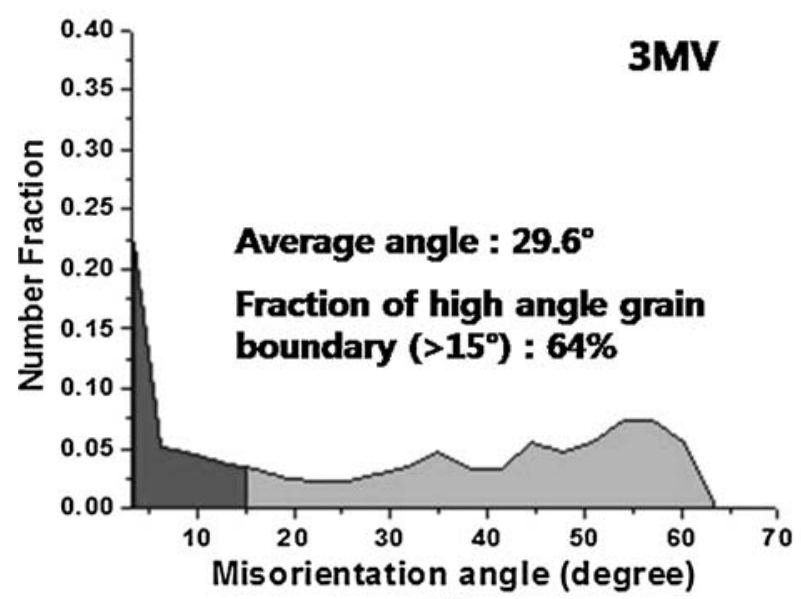

(c)

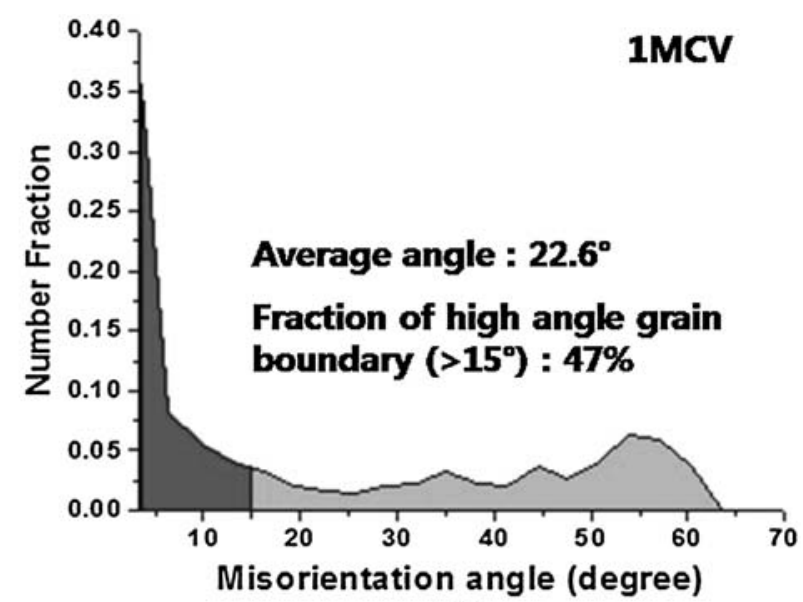

(b)

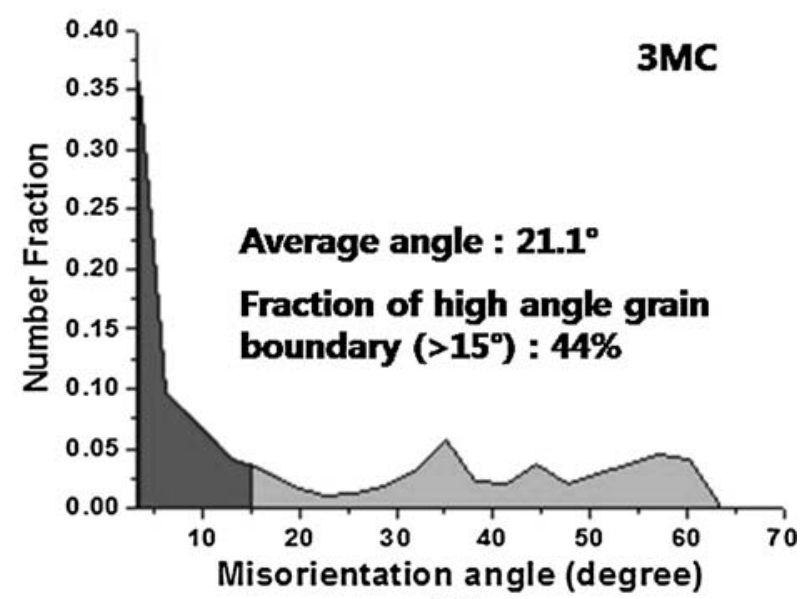

(d)

Fig. 13-Distribution of grain-boundary misorientations of $(a) 3 \mathrm{MCV},(b) 1 \mathrm{MCV},(c) 3 \mathrm{MV}$, and $(d) 3 \mathrm{MC}$ steels.

these analysis data, the correlation between the ETT, the average grain-boundary angle, and the fraction of highangle grain boundaries is presented in Figures 14(a) and (b). The average grain-boundary angle of the $3 \mathrm{MCV}$ steel is $27 \mathrm{deg}$, while that of the $3 \mathrm{MV}$ steel is $30 \mathrm{deg}$. This indicates that the formation of fine GB and a small effective grain size are related to a high fraction of highangle grain boundaries; this fraction is as high as 54 and 64 pct for the $3 \mathrm{MCV}$ and $3 \mathrm{MV}$ steels, respectively, as shown in Figures 13(a) and (c). A higher average grainboundary angle and a higher fraction of high-angle grain boundaries are linearly related to a lower ETT (Figures 14(a) and (b)). This shows a correlation closer than the plotted case between the GB volume fraction and the ETT of Figure 12. The ETT is more affected by the average grain-boundary angle than by the fraction of high-angle grain boundaries, because the former has a larger absolute value of slope than the latter. This implies that the ETT abruptly rises and the lowtemperature toughness deteriorates because of a reduced average grain-boundary angle when grains having many low-angled subgrains, such as GB, are partly present inside, even though the volume fraction of fine, highangled grains such as AF is high. In the present study, the $1 \mathrm{MCV}$ and $3 \mathrm{MC}$ steels show a higher ETT than the other steels, because of their low average grain-boundary angle (approximately $22 \mathrm{deg}$ ) and their low fraction of high-angle grain boundaries (approximately $45 \mathrm{pct}$ ). When grains with large misorientations are distributed finely and homogeneously, the effective grain size and the ETT decrease and the low-temperature toughness can be enhanced. Therefore, for enhanced low-temperature toughness, it is required to refine grains by adding $\mathrm{Mo}$ and $\mathrm{V}$, to reduce the volume fraction of GB and secondary phases by lowering the $\mathrm{Cr}$ content, and to reduce the effective grain size by preventing the formation of coarse GB.

Based on these results, the $3 \mathrm{MV}$ steel is the most excellent steel in terms of strength, USE, and ETT, because its grains are refined with the addition of Mo and $\mathrm{V}$ and its volume fraction of GB and secondary phases is reduced by excluding the $\mathrm{Cr}$ addition. Here, GB is not formed coarsely and the effective grain size is small. In order to address future problems such as increases in the price of the alloying elements or the recycling of resources, more systematic studies on alloying compositions are required. Further studies should be able to present the alloying design and 


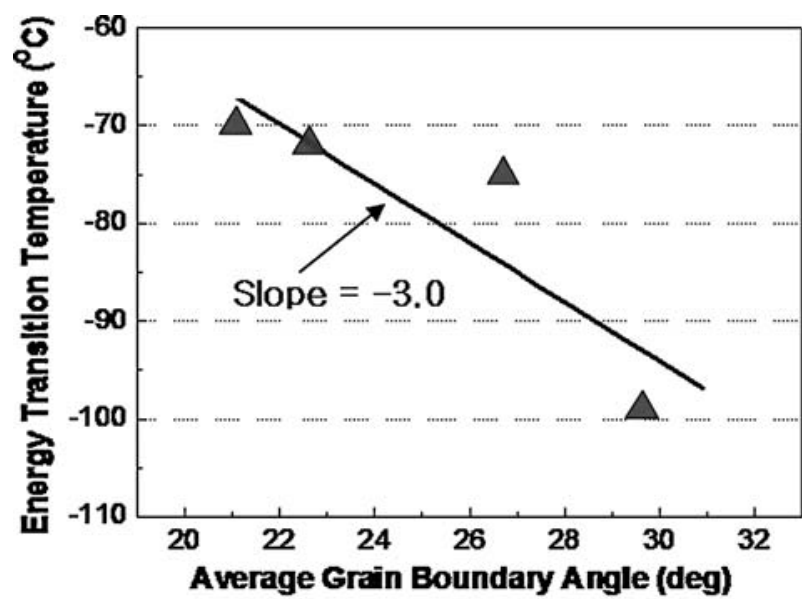

(a)

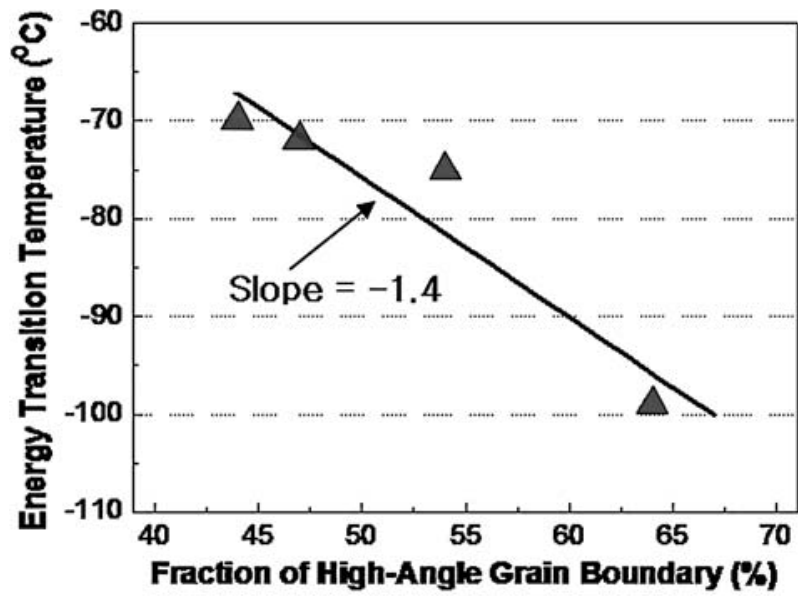

(b)

Fig. 14-Relationship between (a) ETT and average grain-boundary angle and (b) ETT and fraction of high-angle grain boundaries.

processing conditions that are optimal for achieving economical, environmentally friendly pipeline steels with excellent properties.

\section{CONCLUSIONS}

In this study, four API X80 pipeline steels were fabricated by varying the additions of $\mathrm{Mo}, \mathrm{Cr}$, and $\mathrm{V}$, and their microstructures and crystallographic orientations were analyzed to investigate the effects of the alloying compositions on the tensile properties and Charpy impact properties. The following conclusions are drawn.

1. The addition of $0.3 \mathrm{wt}$ pct Mo worked to increase the strength and USE and to decrease the ETT by promoting the fine and homogeneous formation of $\mathrm{AF}$ and $\mathrm{GB}$.

2. The addition of $0.3 \mathrm{wt}$ pct $\mathrm{Cr}$ increased the tensile strength and decreased the USE, because it worked to increase the volume fraction of secondary phases such as MA. It also raised the ETT, because it promoted the formation of coarse GB and an increase in the effective grain size.
3. The addition of $0.06 \mathrm{wt}$ pct $\mathrm{V}$ resulted in higher strength, a higher USE, a smaller effective grain size, and a lower ETT, because it promoted the homogeneous formation of fine AF and GB.

4. In order to increase the strength and USE and reduce the ETT of pipeline steels rolled in the austenite region, it was required to refine grains by adding Mo and $\mathrm{V}$ and to reduce the volume fraction of coarse GB and secondary phases by lowering the $\mathrm{Cr}$ addition.

\section{ACKNOWLEDGMENTS}

This work was supported by the National Research Laboratory Program (Grant No. ROA-2004-00010361-0 (2008)) funded by the Korea Science and Engineering Foundation and by POSCO (Pohang, Korea) under Contract No. 2007Y202.

\section{REFERENCES}

1. J.Y. Koo, M.J. Luton, N.V. Bangaru, R.A. Petkovic, D.P. Fairchild, C.W. Petersen, H. Asahi, T. Hara, Y. Terada, M. Sugiyama, H. Tamehiro, Y. Komizo, S. Okaguchi, M. Hamada, A. Yamamoto, and I. Takeuchi: Proc. 13th Int. Offshore and Polar Eng. Conf., The International Society of Offshore and Polar Engineers, Honolulu, HI, 2003, pp. 10-18.

2. R. Deny: Pipeline Technology, Elsevier, Amsterdam, The Netherlands, 2000, vol. I, pp. 1-116.

3. I. Tamura, H. Sekine, T. Tanaka, and C. Ouchi: Thermomechanical Processing of High-Strength Low-Alloy Steels, Butterworth \& Co., Ltd., London, 1988, pp. 80-100.

4. J. Takamura and S. Mizoguchi: Proc. 6th Int. Iron Steel Congr., ISIJ, Nagoya, Japan, 1990, pp. 591-97.

5. G. Mannucci and D. Harris: Fracture Properties of API X100 Gas Pipeline Steels, Final Report, European Commission, Brussels, Belgium, 2002, vol. 1, pp. 1-128.

6. D.J. Horsley: Eng. Fract. Mech., 2003, vol. 70, pp. 547-52.

7. W.A. Maxey: 5th Symp. Line Pipe Research, AGA, Houston, TX, 1974, catalog no. L30174, pp. 1-21.

8. W.A. Maxey, J.F. Kiefner, and R.J. Eiber: Ductile Fracture Arrest in Gas Pipelines, AGA, Houston, TX, 1976, catalog no. L32176, pp. $1-46$.

9. N. Nozaki, K. Bessyo, Y. Sumitomo, I. Takeuchi, and A. Yamashita: Sumitomo Search, 1981, vol. 26, pp. 76-90.

10. G.M. Wilkowski, W.A. Maxey, and R.J. Eiber: Can. Metall. Q., 1980, vol. 19, pp. 59-77.

11. "API Recommended Practice 5L3: Recommended Practice for Conducting Drop-Weight Tear Tests on Line Pipe," 3rd ed., API Exploration and Production Collection, API, Washington, DC, 1996, 9 pp.

12. N.J. Kim: J. Met., 1983, vol. 35, pp. 21-27.

13. N.J. Kim, A.J. Yang, and G. Thomas: Metall. Mater. Trans. A, 1985, vol. 16A, pp. 471-74.

14. B. Hwang, Y.M. Kim, S. Lee, N.J. Kim, and S.S. Ahn: Metall. Mater. Trans. A, 2005, vol. 36A, pp. 725-39.

15. Y.M. Kim, S.K. Kim, Y.J. Lim, and N.J. Kim: ISIJ Int., 2002, vol. 42, pp. 1571-77.

16. I.D. Choi, D.M. Bruce, D.K. Matlock, and J.G. Speer: Metall. Mater. Int., 2008, vol. 14, pp. 139-47.

17. D.W. Suh, C.S. Oh, and S.J. Kim: Met. Mater. Int., 2008, vol. 14, pp. $175-83$.

18. "ASTM E8M-08: Standard Test Methods for Tension Testing of Metallic Materials," Annual Book of ASTM Standards, ASTM, West Conshohocken, PA, 2008, vol. 03.01, pp. 1-25.

19. "ASTM Standard E23-07: Standard Test Methods for Notched Bar Impact Testing of Metallic Materials," Annual Book of ASTM 
Standards, ASTM, West Conshohocken, PA, 2006, vol. 03.01, pp. 1-27.

20. W. Oldfield: ASTM Standardization News, 1975, pp. 24-29.

21. M. Diaz-Fuentes, A. Iza-Mendia, and I. Gutierrez: Metall. Mater. Trans. A, 2003, vol. 34A, pp. 2505-16.

22. T. Araki: Atlas for Bainitic Microstructures, ISIJ, Tokyo, vol. 1, pp. $1-165$.

23. G. Krauss and S.W. Thompson: ISIJ, 1995, vol. 35, pp. 937-45.

24. Y.M. Kim, S.K. Kim, Y.J. Lim, and N.J. Kim: ISIJ Int., 2002, vol. 42 , pp. $1571-77$

25. F.T. Han, B.C. Hwang, D.W. Suh, Z.C. Wang, D.L. Lee, and S.J. Kim: Met. Mater. Int., 2008, vol. 14, pp. 667-73.

26. Z. Tang and W. Strumpf: Mater. Charact., 2008, vol. 59, pp. 717-28.

27. C. Jing, D.W. Suh, C.S. Oh, Z.C. Wang, and S.J. Kim: Met. Mater. Int., 2007, vol. 13, pp. 13-20.
28. S.J. Kim, C.G. Lee, T.H. Lee, and C.S. Oh: Scripta Mater., 2003, vol. 48, pp. 539-44.

29. M. Honjo and Y. Saito: ISIJ Int., 2000, vol. 40, pp. 914-19.

30. H.W. Swift: J. Mech. Phys. Solids, 1952, vol. 1, pp. 1-16.

31. J.H. Hollomon: Trans. AIME, 1945, vol. 162, pp. 268-90.

32. S.K. Kim, Y.M. Kim, Y.J. Lim, and N.J. Kim: Proc. 15th Conf. Mechanical Behaviors of Materials, Korean Institute of Metals and Materials, Seoul, 2001, pp. 177-86.

33. F.B. Pickering and T. Gladman: ISI Spec. Rep., 1961, vol. 81, pp. $10-20$.

34. N. Okumura: Met. Sci., 1983, vol. 17, pp. 581-89.

35. Y.M. Kim, S.Y. Shin, H. Lee, B. Hwang, S. Lee, and N.J. Kim: Metall. Mater. Trans. A, 2007, vol. 38A, pp. 1731-42. 